\title{
Teorias Constitucionais Progressistas, Backlash e Vaquejada
}

\author{
Progressive Constitutional Theories, Backlash and Vaquejada
}

\author{
Vera Karam de Chueiri ${ }^{1}$ \\ José Arthur Castillo de Macedo ${ }^{2}$ \\ ${ }^{1}$ Faculdade de Direito da Universidade Federal do Paraná, Curitiba, PR, Brasil \\ ${ }^{2}$ Curso de Direito do Instituto Federal do Paraná, Palmas, PR, Brasil
}

\begin{abstract}
Resumo: $O$ artigo parte da relação entre constitucionalismo e democracia nas teorias constitucionais progressistas do campo liberal; especificamente o direito como integridade, o minimalismo judicial e o constitucionalismo democrático, apontando suas diferenças em relação ao papel que atribuem às Cortes na solução das controvérsias constitucionais, como também aos efeitos provocados por suas decisões (backlash). Por fim, discute-se o caso da vaquejada (ADI n. 4.983) para mostrar como tais teorias constitucionais progressistas e suas respostas ao backlash podem servir para iluminar aspectos negligenciados da prática constitucional brasileira, sem, contudo, advogar pela importação de uma ou outra teoria para o Brasil.
\end{abstract}

Palavras-chave: Constitucionalismo Progressista. Backlash. Vaquejada.
Abstract: The article highlights the relation between constitutionalism and democracy in progressive constitutional theories such as law as integrity, judicial minimalism and democratic constitutionalism showing their differences regarding the role Courts have in solving constitutional controversies as well as the effects of their decisions (backlash). Finally, it discusses the vaquejada's case (ADI n. 4.983) in order to show how such progressive constitutional theories and their answers to the backlash can help to enlighten some points that are neglected in our constitutional practice yet without advocating in favor of importing such theories to Brazil.

Keywords: Progressive Constitucionalism. Backlash. Vaquejada.

Recebido em: 10/06/2018

Revisado em: 31/08/2018

Aprovado em: 06/09/2018 


\section{Introdução}

No set of legal institutions or prescriptions exists apart from the narratives that locate it and give it meaning. (Robert Cover in Nomos and Narrative)

O pesquisador Nimer Sultany (2012, p. 373-455) faz uma análise discursiva compreensiva da relação entre constitucionalismo e democracia a partir de determinados autores, suas teorias e as críticas dirigidas a estas. O autor mapeia o campo da teoria constitucional progressista contemporânea de língua inglesa e oferece uma tipologia a partir da relação entre constitucionalismo e democracia. A tipologia proposta pelo autor leva em conta os que: 1) negam a tensão entre constitucionalismo e democracia (Dworkin, Habermas, Ackerman, etc.); 2) pretendem reconciliar as duas categorias (Ely, Sustein, Kramer, Tushnet, etc.); 3) endossam a tensão (Michelman e Tribe); e 4) dissolvem a tensão (Waldron, Parker e Tushnet). Os dois primeiros grupos (dos que negam haver uma tensão entre constitucionalismo e democracia e dos que buscam reconciliá-los) se referem, portanto, aos que defendem um discurso da unidade, no sentido da justificação das democracias constitucionais, enquanto os outros dois grupos (dos que endossam a tensão e dos que a dissolvem) defendem um discurso da não unidade ou separação. Isto é, diferente dos dois primeiros grupos, os dois últimos não defendem um discurso de justificação, na medida em que rejeitam a possibilidade de unir conceitualmente constitucionalismo e democracia (SULTANY, 2012, p. 377).

A primeira constatação de que se parte e que coincide com o argumento de Sultany é a centralidade da relação entre constitucionalismo e democracia para o pensamento politico liberal contemporâneo, mas não só. Ela também é central para o pensamento político progressista não liberal. Para os progressistas liberais, ela se relaciona à justificação dos arranjos políticos e jurídicos, sua autoridade diante de dada comunidade política. Para os progressistas não liberais pode significar uma estratégia de descarte destas categorias, pois qualquer alternativa para uma politica progressista deve ser radical no sentido do descolamento total das insti- 
tuições (MOUFFE, 2013, p. 65). Ou ainda, pode significar, em contraste a essa estratégia de descarte das categorias e do descolamento das instituições, um engajamento a estas com o propósito de forjar uma nova hegemonia (MOUFFE, 2013, p. 71).

Diante da amplitude do debate sobre constitucionalismo e democracia, o assunto deste artigo se restringirá primeiro às teorias constitucionais progressistas do campo liberal ${ }^{1}$ e, em seguida, serão adotadas as seguintes premissas para pensar nas possíveis articulações da relação entre constitucionalismo e democracia: 1) que a autoridade pública deve ser justificada; 2) que todos os membros da comunidade política devem ser tratados com igual respeito e consideração; e 3) que os possíveis desacordos entre os membros da comunidade devem ser reconhecidos e as suas diferenças devem ser igualmente respeitadas.

Para os liberais, a justificação da autoridade não deve impor um ideal de vida boa, isto é, como os cidadãos devem levar suas vidas privadas. Nesse sentido, uma autoridade se justifica ao se tratar de forma imparcial os fins que cada um escolhe, tendo em vista o desacordo generalizado na comunidade e os problemas de ação coletiva. Autoridade, significa, portanto, oferecer boas razões públicas, por meio das quais a ordem política e jurídica se constitui e mantém a sua Constituição. Isso requer algumas condições como a separação de poderes, a centralidade dos direitos fundamentais, o pluralismo, o igual respeito e consideração a todos e todas, o reconhecimento das diferenças e dos diferentes, ou seja, as condições que decorrem dos próprios compromissos assumidos com a forma e a matéria do constitucionalismo e da democracia.

A autoridade justificada com base em boas razões públicas, a constituição da ordem política e jurídica dotada desta autoridade e comprometida com os princípios do constitucionalismo e da democracia não evitam o enfrentamento de questões práticas que desde o início se colocam

\footnotetext{
${ }^{1}$ A exclusão de teorias conservadoras se deve por dois motivos: primeiro, porque o debate no campo progressista já é suficientemente complexo para ser reconstruído nos limites deste trabalho; segundo, um dos objetivos do texto é demonstrar como autores dentro de um mesmo campo progressista que, em tese, possuem afinidades, divergem significativamente a respeito do modo de defender suas preferências teóricas e práticas.
} 
e que dizem respeito à forma de se resolver os desacordos em comunidades plurais e quem devem decidir quando as pessoas discordam, se alguns ou muitos. Além disso, no desdobramento destas questões surgem outras, tais como, se deve ser dado ao povo, diretamente, a decisão sobre as questões que lhe afetam ou apenas aos seus representantes? Ainda, se todas as questões afetas ao povo devem ser decididas por fóruns majoritários ou contramajoritários como, por exemplo, o poder judiciário?

A segunda restrição que se impõe ao objeto deste artigo - sob pena da sua extensão extrapolar os seus propósitos -, diz respeito à discussão que se fará acerca da categoria do backlash, sua importância, expressa ou tácita, para as teorias progressistas liberais.

O campo semântico do termo backlash já foi relacionado com a contrarreação do açoite utilizado contra os escravos, ou com a reação de máquinas. Atualmente, o backlash é utilizado na esfera pública para designar a reação negativa e violenta a condutas, omissões ou decisões, sobretudo de autoridades públicas, mas que pode ser aplicado a pessoas privadas também.

Nesse sentido, à luz das questões já discutidas em relação à democracia, ao constitucionalismo, ao que se estabelece entre ambos, ao papel das instituições, à justificação da autoridade e das decisões que em nome daquelas se toma, o backlash é o ponto para o qual se quer chamar a atenção. Para tanto, recorre-se a três concepções distintas no campo progressista da teoria constitucional: 1) a do direito como integridade de Ronald Dworkin, à qual se refere como direitos, igual respeito e juízes; 2) a do minimalismo de Cass Sunstein à qual se refere como republicanismo, minimalismo, juízes e deferência; e 3) o constitucionalismo democrático de Robert Post e Reva Siegel que é uma crítica às duas concepções progressistas anteriores.

Ao final, será apresentado um exemplo brasileiro, a ADI n. 4.983 (caso da vaquejada), para ilustrar alguns pontos discutidos ao longo do artigo. Acredita-se que, do ponto de vista prático, a discussão das referidas teorias progressistas e das respectivas respostas dadas ao backlash pode contribuir para a melhoria do debate público em um país marcado por uma profunda crise política e de autoridade das instituições constitucio- 
nais ${ }^{2}$. Isso não significa, no entanto, que se deva ou se trate de importar, acrítica e irrefletidamente, uma ou outra teoria para o Brasil.

\section{Dwokin: direitos, igual respeito e juízes}

Em sua obra, Dworkin desenvolve uma teoria constitucional que se articula com as práticas em defesa do ideal de integridade (integrity) e da justiça como equidade (fairness). Para esta teoria, o Poder Judiciário possui um papel central como instituição protagonista na proteção dos ideais de integridade e de justiça como equidade em uma democracia constitucional ${ }^{3}$.

Dworkin é um autor do campo progressista que marca todo debate posterior. Sua crítica ao positivismo dominante no ambiente inglês e norte-americano do final dos 1970 e início dos anos 1980 está calcada num liberalismo político forte, segundo a qual os direitos são trunfos contra a maioria. Esse liberalismo político forte possui um compromisso substantivo com a igualdade. A igualdade é o fundamento da teoria da integridade de Dworkin e ela se concretiza em procedimentos e decisões que se justificam moralmente, na medida em que distribuem poder e reconhecem minorias vulneráveis "[...] não como agentes distintos da comunidade, mas como a comunidade ela mesma. Cada pessoa é tão digna quanto qualquer outra e deve ser tratada com igual respeito." (CHUEIRI, 2016a, p. 284).

Portanto, desde o Taking Rights Seriously (1978) Dworkin defende um liberalismo político fundado na ideia de que todos os cidadãos possuem o direito de serem tratados como iguais, isto é, a eles se exige igual respeito e consideração. Essa formulação diferenciará Dworkin entre os liberais, na medida em que coloca a igualdade na base da sua teoria polí-

\footnotetext{
${ }^{2}$ Por exemplo, quando um dos argumentos centrais a ser considerado por um juiz antes de proferir uma decisão que possa gerar um backlash, é a questão da estabilidade e a manutenção da autoridade das instituições e da Constituição. Trata-se, pois, de questão relevante também para o Brasil na atualidade.

${ }^{3}$ Sobre as divergências de nomenclaturas entre "democracia constitucional" e Estado democrático de direito, ver Nino (2003, p. 5 e ss.).
} 
tica e da sua teoria do direito. A discussão acerca da importância deste valor é retomada em suas obras posteriores para discutir temas como ações afirmativas, igualdade política e unidade do valor. Em Justice for Hedgehogs (DWORKIN, 2011), sua última grande obra, o tema da unidade do valor é central para o nosso argumento acerca da igualdade e seu vínculo com a liberdade ou, melhor, acerca da unidade 'igualdade-liberdade' como razão para justificar a atuação dos juízes nas democracias constitucionais contemporâneas. ${ }^{4}$

A igualdade está integrada com a liberdade (positiva e negativa). Ambas são valores imprescindíveis para uma democracia que é mais do que a vontade da maioria; uma democracia de parceria. Em uma (democracia constitucional) de parceria, a igualdade, isto é, tratar a todos com igual respeito e consideração, não ameaça a liberdade, mas a promove. (CHUEIRI, 2016a, p. 293)

Ao considerar a crítica do autor ao positivismo e ao pragmatismo jurídico que atravessa as suas obras ${ }^{6}$ e cujos argumentos não serão aqui apresentados, sublinha-se a sua contestação à discricionariedade judicial com base na tese da resposta correta, isto é, de que nos casos para os quais não há regras, caberá ao juiz decidir a partir de princípios, os quais forneceram os melhores e mais substanciosos argumentos para justificar uma decisão. Contudo, a justificação dessa decisão não poderá ser feita desconsiderando a história institucional da comunidade na qual o juiz e os cidadãos se inserem. Assim, para Dworkin, o juiz constrói uma decisão (na forma de uma narrativa) buscando integrar as decisões passadas com o presente, de modo a assegurar melhores condições e justificações para que futuras decisões sejam proferidas.

Pois bem, Dworkin não enfrenta a questão do backlash de forma direta mas, indiretamente, ele o faz ao responder como juízes julgam e deveriam julgar casos difíceis, o que nos leva a indagar: Seriam essas decisões políticas? Deveriam os juízes tomá-las em bases políticas? A sua

\footnotetext{
${ }^{4}$ Ver Dworkin (2011, p. 423).

${ }^{5}$ Nesse sentido, também, cf. em Dworkin (2012).

${ }^{6}$ Ver Taking Rights Seriously (1982), A Matter of Principle (1985) e Law's Empire (1986).
} 
resposta a tais indagações é feita em dois níveis: um prático e outro teórico (DWORKIN, 1985).

Do ponto de vista prático, Dworkin enfrenta a objeção feita por aqueles que sustentam que os juízes não devem proferir decisões políticas em casos difíceis, pois suas decisões devem se basear no direito anterior, especialmente nas regras positivadas na Constituição. Decisões que extrapolem estas regras ou que afirmem as convicções políticas do juiz são equivocadas. Para o autor, essa compreensão (rule book based) deixa de lado a consideração de que os juízes devem julgar casos difíceis mesmo que não haja uma regra expressa para tanto. Vale dizer, os juízes devem decidir porque todos os cidadãos da comunidade política são detentores do direito moral de buscar uma resposta do Poder Judiciário à sua demanda. Nesse sentido, é que a decisão é política e deve ser baseada em princípios cabendo ao juiz demonstrar que "[...] his principle to be correct, or at least closer to correct than other principles that are not excluded. So his decision is a political decision in the sense described." (DWORKIN, 1985, p. 17).

Do ponto de vista teórico, ele defende que as decisões proferidas em casos difíceis devem partir de uma concepção de direitos (rights conception), segundo a qual, constitucionalismo e de democracia não são antagônicos, mas complementares e aos juízes e demais autoridades que tomam decisões devem fazê-lo com base em princípios moral e politicamente justificáveis na comunidade política, mas com diferenças próprias das respectivas funções jurisdicional e legislativa ${ }^{7}$. Dworkin critica a idealização do Legislativo como o único com credencias democráticas ou, pelo menos, o principal locus do debate e da tomada de decisão e privilegiado para conhecer a vontade popular e articula-la na forma dos

\footnotetext{
${ }^{7}$ Para o autor, é equivocado achar que o Poder Judiciário seria o responsável por proferir decisões imparciais que aplicam o direito sem tomar posições políticas a respeito dos casos, cabendo ao legislador desenvolver os princípios que estão inscritos na Constituição e esclarecer as ambiguidades ou especificar as leis que necessitem de detalhamento. Ao tomar uma decisão, a fim de instituir uma determinada política, por meio da legislação, o Legislativo asseguraria maior estabilidade política, tendo em vista o seu pressuposto pedigree democrático. A partir dessas leis, o Judiciário poderá julgar os casos de forma imparcial.
} 
seus provimentos. Contudo, essa compreensão do Legislativo ignora fatos notórios como por exemplo, o da hipersensibilidade deste aos interesses de pequenos e poderosos grupos. Além disso, ele tende a ser pouco ou nada sensível às demandas de minorias que são reiteradamente preteridas. O poder econômico também desempenha papel fundamental para sensibilizar os legisladores para certos temas o que se constitui num completo desvirtuamento dos ideais democráticos (DWORKIN, 1985, p. 27).

Para Dworkin, uma democracia constitucional pode e deve contar com a atuação do Judiciário para a resolução de questões difíceis e para a proteção de minorias sistematicamente excluídas. A crítica de que as decisões do Judiciário não são democráticas, ou que em alguns casos extrapolam as suas atribuições, por sua vez, parte de uma descrição implausível do Legislativo. A partir de uma visão mais realista deste fica claro que ele não pode assegurar uma melhor proteção de direitos dos cidadãos e tampouco mais democracia. Portanto, o Judiciário não só pode como deve atuar para resolver casos difíceis.

É óbvio que em vários casos poderá haver controvérsia sobre qual o significado para os enunciados da Constituição, ou, não haverá uma resposta direta para eles. Nesses casos é muito comum que seja levantada uma objeção ao argumento de Dworkin: a questão da estabilidade política. Ora, os poderes públicos devem contribuir para que haja estabilidade do direito e da própria comunidade política. Por isso, decisões cujas fontes e argumentos não estão claros podem ser perigosas para a democracia, no sentido de que - pretensamente - se resolve um problema (um caso) e criam-se outros tantos (dada as reações violentas e negativas ao caso).

Ainda que importante, esta objeção não apresenta argumentos com o peso suficiente para afastar a concepção de direitos. Reconhece Dworkin que a estabilidade política é um ideal a ser cultivado pela comunidade política. Contudo, a comunidade se sustenta em base mais sólida, a justiça. Dworkin $(1985$, p. 25) chama atenção para o fato de que a comunidade política é fundada na justiça que os cidadãos devem as si próprios nas relações que constituem nesta comunidade. Portanto, a demanda de um cidadão que reclama por justiça, isto é, que pleiteia no Judiciário o respeito a um direito seu, deve ser levada a sério. Proferir tal decisão é 
assegurar justamente as bases para que a comunidade continue íntegra. Por outro lado, não lhe assegurar é fomentar condições para o seu esfacelamento.

Todavia, algum cético poderá questionar como se dará a concretização desse ideal. A resposta, apesar de direta, não é simples. Em primeiro lugar, o Judiciário deve tratar o direito como integridade, o que requer de suas decisões coerência e justificativas baseadas em princípios. A comunidade poderá debater a justificação apresentada e até mesmo trazer, em outros casos e momentos, princípios diversos que ofereçam argumentos mais robustos para fundamentar novas decisões. Este debate constituirá aquilo que Dworkin chama de o fórum de princípios. Em segundo lugar, caberá ao Judiciário reforçar o direito de igualdade compreendido como o direito a ser tratado igualmente pela comunidade política. É a igualdade, aliás, o elo entre o constitucionalismo aqui tomado pela concepção dos direitos e a democracia, pelo fato de que ela garante que não haja discriminações injustas que violam tanto um quanto outro.

É notável a distinção que Dworkin faz no Justice for Hedgehogs (2011, p. 385) entre dois modelos de democracia: a majoritária e a de parceria. Na primeira, a maioria possui uma autoridade moral para decidir questões controvertidas para todos, enquanto na segunda

[...] (the partnership conception), a majority has no moral authority to decide anything unless the institutions thorough which it governs are sufficiently legitimate. Judicial review is one possible [...] strategy for improving a government's legitimacy - by protecting a minority's ethical independence, for instance - and in that way securing a majority's moral title to impose its will on other matters. (DWORKIN, 2011, p. 385)

Portanto, ainda que a estabilidade política seja importante, o Judiciário é responsável por assegurar os direitos fundamentais dos cidadãos, os quais, muitas vezes, serão trunfos contra a maioria, a despeito das possíveis reações contrárias à decisão. Em outras palavras, para o juiz dworkiniano, este não pode se guiar por receios de reações violentas (backlash) e ultrajantes, pelo contrário, deve justamente reafirmar o compromisso da comunidade com a justiça e o igual respeito a cada cidadão. 
Ainda que o backlash não seja pontualmente enfrentado por Dworkin, ele está compreendido na sua defesa dos direitos por meio do protagonismo judicial, em especial, o judicial review; trunfos contramajoritarios que não devem capitular diante de reações adversas de maiorias orientadas por racionalidades convencionais ou pragmatistas/consequencialistas. Daí discutir-se na sequência a teoria do minimalismo judicial de Cass Sustein que, além de estar entre os liberais progressistas que, sensíveis à relação entre constitucionalismo e democracia, é um crítico de Dworkin e um dos pontos da sua crítica diz respeito ao backlash.

\section{Cass Sunstein: republicanismo, minimalismo, juízes e deferência}

Cass Sunstein, considerado um dos autores do Republican revival, juntamente com Frank Michelman e outros constitucionalistas, desenvolveu ao longo dos anos 1990, teorias que criticavam a defesa da neutralidade política do Estado e a restrição à liberdade de expressão ${ }^{8}$. No início dos anos 2000, Sunstein defendeu a promulgação de um Second Bill of Rights, com o objetivo de fomentar o compromisso dos poderes públicos com os direitos sociais. Porém, mais relevante para o presente texto são suas ideias a respeito daquilo que ele chama de minimalismo judicial ${ }^{9}$.

Segundo o autor desde os tempos dos pais fundadores se pautou a construção de uma república de razões, na qual o processo deliberativo é central para a vida política. Nessa República, o Estado deve promover a igualdade, a liberdade, a cidadania e a deliberação pública. Contudo, tal tarefa não é de competência exclusiva de um só poder. Justamente o contrário, cabe a todos os poderes assegurar a proteção dos direitos fundamentais, mas o protagonismo na deliberação pública deve ser dos representantes eleitos ou da cidadania. Na obra a The Partial Constitution (1993), Sunstein desenvolve essas ideias e já defende, ao contrário de Dworkin, um papel restrito do Judiciário na democracia estadunidense.

O autor preocupa-se, antes, com o fortalecimento de uma democracia deliberativa para a qual é necessário que o debate público seja robusto

\footnotetext{
${ }^{8}$ Ver Sunstein (1988), Sunstein (1993) e Sunstein (1995).

${ }^{9}$ Em língua portuguesa ver Sampaio (2008, apresentação) e Pires (2011, p. 131-157).
} 
não bastando que haja qualquer debate. Assim, o Judiciário deverá atuar de forma forte para que sejam asseguradas as condições para a implementação da democracia deliberativa, o que significa dizer, ele deve promover a desobstrução de canais de comunicação (ampliando a liberdade de expressão); a garantia do acesso a mais informações; a proteção da igualdade política e da deliberação em si mesma. Além dessas hipóteses, não deve o juiz adotar uma postura ativa, pois pode prejudicar a democracia e o autogoverno coletivo baseado no debate livre e robusto.

As reflexões do autor desembocam em uma concepção ainda mais restrita da atuação judicial: o minimalismo judicial. Note-se que desde os seus escritos a respeito do republicanismo cívico, Sunstein já defendia um papel reduzido do Judiciário, portanto, sob este aspecto, não houve grande mudança em sua posição teórica. Não obstante, sua defesa do minimalismo judicial reivindica, ao longo do tempo, uma forma mais radical, sugerindo um "encolhimento" maior do papel do Judiciário, especialmente em questões controversas. Isso se dá em razão do seu compromisso com a democracia como autogoverno coletivo - nos primeiros trabalhos - e com a democracia deliberativa. Ao considerar outros trabalhos de Sunstein, especialmente o artigo Interpretation and Institutions, escrito com Adrian Vermuele (2003, p. 885-951), no qual ele faz uma crítica às teorias idealizadas da interpretação constitucional e defende a preocupação com os efeitos da interpretação e com as capacidades institucionais, nota-se que ao dialogar com outros saberes - especialmente a economia - o autor se deixa influenciar por estes. Não se está afirmando que isso seja ruim em si, pois, obviamente, não é.

Todavia, o que é questionável é a forma pouco crítica com que Sunstein adere a certos raciocínios econômicos e transporta a defesa de certa racionalidade instrumental para o campo do direito sem maiores ponderações e/ou críticas. A racionalidade consequencialista, celebrada pelo main stream da teoria econômica, é importada para o direito sem algumas mediações ou esclarecimentos sobre como ela deve ser operada em raciocínios a respeito de direitos e questões relacionadas à justiça da comunidade. 
O minimalismo advoga uma postura mais deferente do Judiciário, especialmente em questões controversas de ordem moral e politica, nas quais as decisões a ser tomadas podem ensejar o aumento daquelas. Em razão disso, deve a Suprema Corte, por exemplo, saber utilizar aquilo que Alexandre Bickel (1986, p. 205-207) chamou de virtudes passivas ${ }^{10}$. Tais virtudes consistem no bom uso da prudência, da sensibilidade política e do silêncio. Em outras palavras, significa que em muitas situações a Suprema Corte poderá demorar mais tempo para decidir uma questão em razão da convulsão social que, por outro lado, ela pode causar. Segundo esse raciocínio, o tempo da tomada de decisão pode fazer toda a diferença para a sua qualidade e autoridade futura.

Além disso, contrariando a posição de Dworkin, o minimalismo defende que as decisões judiciais proferidas nos casos difíceis devem, preferencialmente, ser curtas e rasas. A pequena extensão da decisão e a ausência de profundidade, contribuiriam, em tese, para impedir equívocos evitáveis (SUNSTEIN, 2006, p. 7; GODOY, 2017, p. 124-125). Em muitos casos, os tribunais em geral carecem também de capacidade institucional para analisar determinadas matérias - o que é correto em casos nos quais há controvérsias do campo científico (SUNSTEIN; VERMUELE, 2003). Essa foi a postura adotada, por exemplo, pela ex-ministra do STF, Ellen Gracie, no julgamento da ADI n. 3.150, conforme relembra Thula Pires (2011, p. 144-146) ${ }^{11}$.

Por fim, outro aspecto fundamental do minimalismo é a desnecessidade de que a decisão judicial seja justificada em acordos completamente teorizados. Isto significa dizer que, para um minimalista, é possível atingir acordos sobre algo importante mesmo que se discorde muito. Tais acordos tem duas formas principais:

First, people may agree on an incomplete theorized abstraction, involving (for example) freedom of speech, due process of law, sex equality or clean air, even when they disagree on what those abstractions should mean in practice. [...] Second, people may agree

\footnotetext{
${ }^{10}$ Ver, ainda, Godoy (2017, p. 115).

${ }^{11}$ A ADI n. 3.510 tinha como pedido a declaração da inconstitucionalidade da Lei n. 11.105/2005, que autorizou o uso de células-tronco embrionárias para a pesquisa científica.
} 
on specific outcomes, even when they disagree about fundamental values that account for them. These, then, are incompletely theorized agreements on particular results, which are [...] much the stuff of law. (SUSTEIN, 2018, p. xi)

Trata-se de outro ponto no qual o minimalismo de Sunstein difere do direito como integridade de Dworkin, na medida em que sustenta a ideia de que uma pessoa pode acreditar em algo da forma como ela quiser e outra pessoa pode também fazê-lo. Ambas podem se respeitar e conviver nos termos acordados, mesmo que suas crenças não coincidam.

Ao contrário de Dworkin, Sunstein enfrenta diretamente o questionamento se deveriam os juízes dar atenção à reação popular (popular outrage) em suas decisões. A princípio, ele reconhece que se os juízes começarem a levar em consideração a reação popular negativa e violenta, isso pode ferir a independência judicial. Entretanto, ele afirma que por razões consequencialistas e epistêmicas os juízes deveriam levar em consideração as reações do público nas suas decisões. Para explicar essas razões, ele lança mão de três exemplos de juízes (2007, p. 162 e ss.).

O primeiro seria o juiz kantiano, o qual profere a decisão correta independentemente das consequências. Hércules de Dworkin, com certeza seria um juiz dessa linha, um juiz herói. O segundo exemplo é o juiz Bentham que leva em consideração as possíveis consequências de suas decisões antes de toma-las e, por isso, é considerado um consequencialista. O terceiro, é o juiz Condorcet o qual crê que o público pode prover informações relevantes para conhecer qual é a resposta mais correta a respeito do tema. Ele entende que a indignação do público pode ser um indício de qual é a melhor resposta. Suas preocupações são de ordem epistêmica.

Em alguns raros e importantes casos, o juiz Bentham levará em consideração os possíveis efeitos de suas decisões. Contudo, isto não deverá ocorrer em qualquer circunstância, porque a decisão a ser proferida, produzirá uma revolta popular (outrage) e, será, ao mesmo tempo intensa e danosa. Logo, não será aplicado o raciocínio consequencialista a qualquer decisão polêmica. Segundo Sunstein $(2007$, p. 159) "[ ... (i)t is tempting to reject that assumption and to think that judges should rule as 
they see fit even if the heavens would fall. But if the heavens really would fall, perhaps judges should not rule as they see fit".

Sublinha-se que ignorar a reação do público pode gerar uma série de efeitos nefastos, exemplificados em três tipos de decisão: 1) A que pode se tornar fútil e dispensável, porque simplesmente será ignorada; 2) A que pode ser pervertida, isto é, ela produzirá consequências distintas daquela que a Corte esperava; e 3) A que pode produzir um mal maior. Tais exemplos de decisão reforçam o argumento a favor da postura consequencialista do juiz Bentham.

Há outra situação relevante, na qual uma postura consequencialista, curiosamente, leva a um comportamento kantiano. Pessoas que ocupam determinadas funções e papéis sociais, muitas vezes possuem, ou, se espera que possuam, aquilo que se chama de role morality, uma moralidade decorrente da sua função ou papel social. O resultado da role morality é que se espera de determinados agentes que atuem conforme os seus papéis institucionais. Assim, espera-se de juízes o julgamento imparcial mesmo que haja a pressão do público ou de grupos específicos. Para Sunstein, poderá ocorrer situações nas quais agir contrariando a role morality pode ensejar uma reação do público, por violação a expectativa gerada por anos de atuação conforme o papel exercido em determinada função. Nesse caso, agir de forma consequencialista, de acordo com as expectativas do público, resulta em uma ação aos moldes kantianos.

Por fim, segundo o juiz Condorcet, uma intensa oposição do público é uma pista de que a sua interpretação da Constituição é incorreta. Essa concepção é baseada no argumento do teorema do Júri de Condorcet, o qual sustenta que se cada membro de um grupo de pessoas que está por decidir algo, tender a adotar a decisão correta, a probabilidade de que essa decisão seja correta aumenta conforme aumentar o número de pessoas que decidirão (NINO, 2003, p. 178 e 395). Esse raciocínio pode ser útil quando houver grande controvérsia a respeito de um tema moralmente polêmico.

Não obstante, o juiz Condorcet tem razões mais fracas para defender a atenção do juiz às possíveis reações à sua decisão. Um dos problemas é a reprodução na sociedade de visões desinformadas, as quais 
podem ser decorrentes: 1) de enviesamentos sistemáticos; 2) de uma cascata, um efeito dominó em matéria de informações; e 3) do fenômeno de polarização dos grupos, o que pode empurrar todo um grupo para uma posição extrema (SUNSTEIN, 2003a). As três patologias geram visões desinformadas e impedem que haja a independência de raciocínio exigida para a realização do teorema de Condorcet.

Portanto, para Sunstein, são poucos e excepcionais os casos nos quais os juízes devem levar em consideração as possíveis reações do público. Para ele, decisões que possam gerar uma reação violenta do público, devem ser evitadas se houver clara e consistente informação sobre a possível reação e, ainda, quando forem preenchidas as condições do teorema de Condorcet. Nestas situações, devem ser aplicados os conselhos minimalistas a respeito do bom uso das virtudes passivas de Bickel, da vantagem da hesitação ou de decisões curtas e limitadas. A despeito disso, ele reconhece que haverá situações nas quais a decisão menos prejudicial será a kantiana. Nessas decisões, entende-se que, de alguma forma, Sunstein dá razão ao uso do argumento dworkiano.

\section{Rieva Siegel e Richard Post: constitucionalismo democrático e backlash}

A terceira e última corrente liberal progressista analisada neste artigo é o constitucionalismo democrático defendida por Robert Post e Reva Siegel. O constitucionalismo democrático difere-se, de um lado, à esquerda, das propostas mais críticas ao judicial review norte americano como o constitucionalismo popular e o experimentalismo, ou seja, os autores não compreendem a jurisdição constitucional como necessariamente contrária à democracia. Segundo eles, é necessário verificar o arranjo institucional, o modo de interpretar a constituição e a suas relações com a sociedade para que se possa criticar a jurisdição constitucional. De outro lado, à direita, o constitucionalismo democrático representa uma reação à ascensão conservadora na política e no direito estadunidense e seus reflexos sobre o arranjo entre constitucionalismo e democracia com foco no papel da jurisdição constitucional. Sob este viés, o constitucionalismo democráti- 
co é progressista (no sentido político da expressão) que se contrapõe às propostas conservadores que defendem o originalismo como estratégia de contenção do projeto constitucional liberal iniciado pela Corte Warren (JARAMILLO apud SIEGEL; POST, 2013, p. 11).

Se fosse possível produzir uma escala entre as diferentes teorias liberais progressistas até aqui discutidas, marcando as distintas posturas a respeito do papel atribuído ao juiz na resolução de casos difíceis ou controversos, seria possível afirmar que nos dois extremos dessa escala está Dworkin, de um lado, e Sunstein, do outro. Numa ponta o juiz virtuoso, herói - arrogante, no dizer de Sustein - cuja interpretação oferecerá as melhores e mais elaboradas razões para a aplicação da constituição em casos difíceis com fundamento em princípios. Na outra ponta, o juiz soldado, deferente às decisões majoritárias dos representantes do povo (GODOY, 2017, p. 121). O constitucionalismo democrático pode ser situado no meio dessa escala. Porém, isso não significa afirmar que ele seja menos crítico, pelo contrário, o constitucionalismo democrático é a concepção mais crítica das três.

O constitucionalismo democrático não vê com o entusiasmo de Dworkin o protagonismo do Poder Judiciário, tampouco cede às exortações minimalistas em defesa das virtudes passivas. Para Siegel e Post, o foco da teoria constitucional progressista não é nem pode estar na Jurisdição constitucional, na figura do juiz virtuoso ou do juiz silencioso, mas em uma interessante articulação entre o direito e a política numa sociedade plural e heterogênea. Vale dizer, Siegel e Post (2013, p. 49) desenvolvem uma teoria constitucional para proteger os direitos constitucionais em contextos de conflito (SIEGEL; POST, 2007, p. 374). O desacordo e o conflito são tomados como condições normais para o desenvolvimento do direito constitucional e qualquer tentativa de evitá-los ameaça tanto a política quanto o direito - tanto a democracia quanto o constitucionalismo (CHUEIRI, 2016, p. 241)

Nesse ponto, importam as considerações de Siegel e Post (2007, p. 376) sobre o backlash que 
"[...] expresses the desire of a free people to influence the content of their Constitution, yet backlash also threatens the independence of law. Backlash is where the integrity of the rule of law clashes with the need of our constitutional order for democratic legitimacy.

Tendo como referência o caso Roe v. Wade ${ }^{12}$ e a fúria que a decisão produziu (ao autorizar o aborto), os autores afirmam que o pêndulo das explicações acerca do papel dos tribunais na democracia americana oscilou muito. Por sua vez, eles oferecem uma explicação mais ampla e realista acerca do fato e, para tanto, sublinham a questão da estabilidade política.

O constitucionalismo democrático considera central o debate a respeito da autoridade da Constituição, a qual deve ser compreendida num contexto de conflito a respeito dos seus significados. Para os autores, é necessário compreender que os movimentos sociais buscam mobilizar argumentos com e contra a Constituição a favor de suas lutas.

No caso Roe versus Wade, isso fica muito claro diante dos argumentos e ataques conservadores que tornaram a discussão sobre o aborto, uma discussão sobre o sentido de família ou sobre o exercício da liberdade de crença. $\mathrm{O}$ caso também levantou uma controvérsia federativa acerca das competências da jurisdição estadual e federal -diante da legislação conflitante relacionada aos direitos à vida e sua interrupção- levando a discussão a refletir sobre a alteração daquelas, como também, sobre transladar matérias que são públicas para a esfera privada.

Nesse sentido, tomando as controvérsias constitucionais em um sentido mais amplo, o constitucionalismo democrático amplia a compreensão da complexidade dos conflitos e sugere que controvérsias provocadas por decisões judiciais trazem efeitos benéficos, na medida em que provoca os cidadãos a se manifestarem - em favor ou contra- às decisões e, assim, a participarem na construção dos sentidos da Constituição. Isso desloca das Cortes para o povo a tarefa de atribuição de sentido da Constituição e dei-

\footnotetext{
${ }^{12}$ Roe versus Wade, 410 U.S. 113 (1973) é uma histórica decisão de 1973, da Suprema Corte dos Estados Unidos, acerca da (in)constitucionalidade das leis que criminalizavam ou restringiam a realização de aborto.
} 
xa de se ter um constitucionalismo centrado na opinião daquelas em favor para um constitucionalismo que a submete ao crivo popular e intenta promover a mediação entre ambas. Isso agrega legitimidade democrática ao significado constitucional e aposta na importância do backlash, isto é, das reações violentas e populares geradas por decisões judiciais.

Em razão disso, Siegel e Post sustentam que é um erro dizer que o foco das teorias progressistas deve ser o método de interpretação, como quer Dworkin. Por outro lado, é igualmente equivocado o minimalismo que tende a privilegiar o status quo, ao invés de estimular a transformação social. Isto significa que a despeito da crítica minimalista de Sustein para quem é melhor para a agenda progressista liberal que as Cortes se mantenham discretas e neutras diante de interpretações divergentes acerca dos diretos constitucionais em casos controversos (como o caso Roe versus Wade acerca do abroto) ou da defesa de Dworkin do protagonismo das Cortes em fazer valer os direitos constitucionais fundamentais em casos como este, com base em princípios que internalizam os compromissos morais de dada comunidade, o constitucionalismo democrático de Siegel e Post (2009, p. 26) propõe uma alternativa positiva e não normativa:

Our analysis is positive, not normative. The object of these brief reflections is to situate questions about interpretative method that have dominated constitutional theory in the last several decades in a dynamic understanding of our constitutional order.

Essa análise positiva das controvérsias constitucionais permite que os autores vislumbrem aspectos teóricos, interpretativos e institucionais, discutidos por Dworkin e Sunstein, sem descuidar de outras dimensões relevantes. Por isso, ao analisarem a questão do backlash eles afirmam que essa questão não tem somente um aspecto negativo, tal como vislumbrado por Sunstein. O backlash pode ser compreendido como algo positivo ao estimular as disputas sobre os sentidos profundos (a identidade) da Constituição, aquilo que Robert Cover chamou de nomos ${ }^{13}$. Quando

\footnotetext{
${ }^{13}$ No set of legal institutions or prescriptions exist apart from the narratives that locate it and give it meaning. For every constitution there is an epic, for each Decalogue a scripture. Once understood in the context of the narratives that give it meaning, law
} 
a identidade constitucional está em disputa, essa querela pode reforçar a autoridade da Constituição, ao contrário do que parece entender Sunstein. Esse é um dos motivos apresentados para criticar o minimalismo, o qual sustenta que as decisões judiciais devem evitar a contestação da pluralidade de modos de vida e de expressão. Nesse sentido, Sunstein afirma que Roe versus Wade foi uma decisão incorreta pois o assunto era controverso. Daí a defesa de decisões curtas e limitadas. Não obstante, subjaz a esse raciocínio, o respeito aos diversos modos de vida. Assim, Siegel e Post (2013, p. 108) indagam: o que significa respeito para o minimalismo? Segundo os autores há dois sentidos minimalistas para a 'respeito': 1) a decisão não pode ser controversa para evitar o conflito constitucional; 2) os tribunais devem decidir os casos de forma que não sejam considerados criticáveis por grupos antagônicos. O minimalismo não é claro sobre qual sentido é adotado. Além disso, para Siegel e Post o primeiro sentido de respeito é implausível, pois, segundo este, uma decisão controversa, porém correta, como a do caso Brown versus Board of Education ${ }^{14}$, não poderia ser proferida.

Siegel e Post (2013, p. 109-110) não menosprezam o fato de que, em alguns casos, é mais prudente evitar o conflito. Todavia, ainda que o conflito constitucional seja custoso, reconhecem as funções sociais construtivas que tem o desacordo social. Como exemplo de enfrentamento da controvérsia moral de forma construtiva, os autores citam a decisão do Caso Casey ${ }^{15}$, no qual os juízes empregaram parâmetros que mediaram o conflito e o canalizaram para diálogo público.

becomes not merely a system of rules to be observed, but a world in which we live in. Ver Cover (1999, p. 96).

${ }^{14}$ Brown versus Board of Education of Topeka, 347 U.S. 483 (1954) é uma decisão histórica da Suprema Corte dos Estados Unidos, acerca da (in)constitucionalidade das leis que autorizavam escolas e transporte escolar separados para negros e brancos, reiterando a discriminação racial nos EUA.

${ }^{15}$ Planned Parenthood versus Casey, 505 U.S. 833 (1992) é uma decisão histórica da Suprema Corte dos Estados Unidos, na qual se questionou a constitucionalidade de várias leis do estado da Pensylvania acerca da restrição ao aborto. Diferente do caso Roe v. Wade, em Planned Parenthood versus Casey o estado pode regular o aborto no primeiro trimestre ou em qualquer outro momento, antes ou depois do momento mais viável, na medida em que tal regulação não signifique um ônus ou risco relativamente ao aborto. 
Relacionar respeito ao caráter neutro dos tribunais em relação a perspectivas constitucionais rivais e antagônicas é um equivoco, na medida em que há casos nos quais os tribunais tem que escolher entre concepções distintas, como é, por exemplo, o caso do aborto. Portanto, não há espaço para neutralidade nessas matérias.

É possível afirmar que o constitucionalismo democrático fornece um quadro mais interessante e comprometido - com o seu nome e o seu nomos - para lidar com um contexto de complexa disputa a respeito dos sentidos da Constituição. Também contribui para manter aceso o vínculo entre política e direito, sem descurar da autoridade da Constituição. Esta perspectiva pode ser interessante para tentar compreender os conflitos constitucionais do Brasil contemporâneo. Nesse sentido, conclui-se este artigo com um exemplo de caso constitucional controverso enfrentado por nosso Supremo Tribunal Federal (daqui em diante STF), a vaquejada.

\section{Conclusão e um exemplo: o STF e a vaquejada}

Nesta parte final do texto, à luz da ADI n. 4.983, julgada pelo STF e conhecida como o caso da vaquejada, retoma-se as teorias constitucionais progressistas discutidas, destacando os dilemas da democracia constitucional brasileira no caso e na respectiva decisão que dividiu a Corte numa votação de resultado 6 a 5, a favor da inconstitucionalidade da lei questionada.

Se nosso propósito era falar da tensa relação entre constitucionalismo e democracia e da maneira como ela é compreendida pelo constitucionalismo progressista de Dworkin, Sustein, Post e Siegel, com foco na teoria e na prática do backlash, as nossas considerações finais, para além de apontar os principais argumentos da nossa reflexão, remetem à esta recente controvérsia constitucional o STF acerca da proteção das manifestações culturais e a preservação do meio ambiente, mas não só. Trata-se, em nossa opinião, de um caso exemplar não só pelo conflito entre direitos fundamentais, mas também pelo conflito acerca do próprio sentido da Constituição. 
Ressalva-se que nosso objetivo não é transpor as teorias apresentadas como a melhor forma de interpretar o contexto brasileiro. Pelo contrário, o diálogo com as teorias estrangeiras pode ser a faísca para reflexões que partam do caso. Daí a vaquejada possibilitar pensar a democracia constitucional brasileira, quem fala por ela e como fala. Afinal, como na epígrafe do trabalho, reitera-se que nenhuma instituição ou prescrição existe aparte das narrativas que as localizam e lhes dão significado.

Em 6 de outubro de 2016, o STF proferiu a decisão na ADI n. 4.983, ajuizada pelo Procurador Geral da República, contra a Lei n. 15.299/2013, do Estado do Ceará, que regulamentava a prática - esportiva e cultural, segundo a lei - da vaquejada ${ }^{16}$.

A controvérsia entre a proteção das manifestações culturais, conforme dispõe o artigo $215, \S 1^{\circ}$ e a preservação do meio ambiente, conforme dispõe o artigo 225, $\S 1^{\circ}$, inciso VII, ambos da Constituição Federal (CF), foi levada à pauta do STF por meio da referida $\mathrm{ADI}$, a qual passou a ser referida como o caso da vaquejada. Este se tratou de um caso difícil, na medida em que se tinha de um lado o direito às manifestações esportivas e culturais e, de outro, o direito à proteção da fauna e a consequente vedação de práticas que impliquem em extinção de espécies ou submetam os animais à crueldade.

O STF julgou a lei inconstitucional por uma apertada maioria, isto é, o resultado da decisão foi de seis votos a cinco. Em suma, entendeu essa apertada maioria que a prática cultural de entretenimento conhecida como vaquejada, cuja regulamentação a lei atacada propunha-se realizar, submete o animal bovino à crueldade, ainda a regulamentação buscasse impedir o seu sofrimento.

A minoria, por sua vez, argumentou que a vaquejada consiste no modo de criar e viver da população sertaneja, vale dizer, uma prática cultural que deveria ser regulamentada para evitar o que seria pior, a sua crueldade.

${ }^{16}$ Agradecemos ao Erick Kiyoshi Nakamura, estudante-pesquisador de graduação da Faculdade de Direito da UFPR pela sua pesquisa acerca da vaquejada. 
Do ponto de vista democrático, anota-se que nesse caso não houve um debate mais ampliado com a comunidade envolvida, seja nos meios institucionais pela via das audiências públicas, seja nos meios socialmente organizados (instituições não governamentais ambientais, associações culturais, etc.), como também nas comunidades em que tal prática ocorre.

Em 19 de outubro de 2016, o Senador Otto Alencar (PSD/BA) apresentou uma Proposta de Emenda à Constituição (PEC n. 50/2016) para incluir o $\S 7^{\circ}$ ao artigo 225 da $\mathrm{CF}$, no sentido de permitir a realização das manifestações culturais registradas como patrimônio cultural brasileiro que não atentem contra o bem-estar animal ${ }^{17}$. A PEC n. 50/2016 foi aprovada em 14 de fevereiro no Senado e enviada à Câmara (PEC n. 304/2017). Nessa Casa foi aprovada em 31 de maio de 2017 e promulgada pela Mesa das duas Casas em 6 de junho de 2017 tornando-se a EC n. 96/2017 $7^{18}$.

A seguir, em julho de 2017 nova ação foi ajuizada (ADI n. 5.728), cujo relator é o Ministro Toffoli, ainda pendente de julgamento. A Procuradoria Geral da República também apresentou outra ADI n. 5.772, cujo relator é o Ministro Barroso. Em ambos os processos a Advocacia Geral da União manifestou-se pela improcedência das ações, portanto, pela constitucionalidade da Emenda n. 96/2017 e da prática cultural e esportiva da vaquejada ${ }^{19}$. O julgamento destas ações se encontram pendentes de julgamento pelo STF.

Destaca-se um fato pouco noticiado na imprensa do Sul e do Sudeste: houve uma rápida e significativa mobilização por parte da população nordestina ligada à esta prática esportiva-cultural. Em Salvador, em Brasília e em outras cidades, além de manifestações a favor da prática, houve a defesa da prática por meio de adesivos colocados em carros e caminhões. Essa mobilização foi além da rápida resposta congressual, a qual poderia

\footnotetext{
17 Disponível em: https://www25.senado.leg.br/web/atividade/materias/-/ materia/127262 Acesso em: 25 maio 2018.

${ }^{18}$ Idem.

${ }^{19}$ Conforme Manifestação da AGU na ADI n. 5.772, deveria a ação ser encaminhada ao Ministro Dias Toffolli, o qual estaria prevento para julgar a matéria já que ele é o relator da ADI n. 5.728.
} 
induzir, equivocadamente, a ideia de que houve uma resposta legislativa (de uma elite) à decisão judicial proferida pelo STF (outra elite). Tanto a reação popular quanto a legislativa, ambas imediatas ao fato, desafiaram várias interpretações a respeito do tema, expondo as múltiplas vozes que dão sentido à Constituição, seus princípios, suas diretrizes e seus possíveis arranjos.

$\mathrm{Na}$ esteira das teorias constitucionais progressistas discutidas, quais sejam, o direito como integridade, o minimalismo e o constitucionalismo democrático, o caso vaquejada suscitaria (como de fato suscitou) distintas interpretações. Por exemplo, uma interpretação minimalista questionaria: por que o STF decidiu a questão? Ou, por que o STF decidiu a questão contra a prática cultural nordestina por uma margem tão apertada? $\mathrm{Ou}$ ainda, por que o STF não proferiu uma decisão menos profunda?

Uma interpretação baseada em princípios, defenderia uma compreensão específica do meio ambiente e questionaria o tipo de relação da comunidade brasileira com aquele, especificamente em relação ao trato "ético" com os animais e o faria assumindo que é dado ao STF fazer o controle de constitucionalidade da lei estadual. Assim fez o Ministro Barroso em seu voto pela inconstitucionalidade da referida lei. O Ministro Marco Aurélio, por sua vez, recorreu à história institucional e às decisões anteriores proferidas pelo STF, nos casos da rinha de Galo e da Farra do Boi, para fundamentar o seu voto no sentido da inconstitucionalidade. Um argumento de princípio também poderia ser usado para defender a constitucionalidade da vaquejada ao reconhece-la como a expressão de um dado modo específico de vida, diverso do modo urbano predominante na sociedade brasileira atual. Tratar a todos com igual respeito e consideração de modo a não isolar ou oprimir uma minoria cujas práticas colidam contra os anseios da maioria poderia, nesse caso, ser uma justificação para a validade da lei em face da Constituição. O Ministro Fachin que votou pela constitucionalidade da lei assim interpretou a vaquejada, isto é, como uma prática cultural que consiste no modo de criar, fazer e viver da população sertaneja.

Do ponto de vista do constitucionalismo democrático se questionaria se a reação legislativa à vaquejada, considerando-a como prática cul- 
tural, não seria uma forma da própria comunidade definir, por meio de seus representantes, o que constitui o seu nomos? Em outras palavras, o aparente desafio por parte do Congresso à autoridade da decisão da Corte, poderia ser interpretado como uma disputa sobre quem é a autoridade mais legítima para definir a intepretação constitucional a respeito dessa prática. Além da questão sobre quem é o sujeito que pode falar em nome do povo, reside a substância do conflito constitucional, isto é, se a prática da vaquejada é uma prática cultural e esportiva legítima e não envolve, necessariamente, a prática de maus tratos de animais (artigo $225, \S 1^{\circ}$, inciso VII CF). Nessa linha, mais do que identificar qual é a melhor resposta, é fundamental ter em conta que a mobilização da população e de movimentos sociais, com o objetivo de influenciar os poderes constituídos (o Congresso Nacional ou o STF) reforça a autoridade da Constituição, porquanto o centro da disputa é a interpretação dos dispositivos que foram analisados pelos ministros do STF ao analisar a ADI n. 4.983.

A autoridade da Constituição é revigorada porque os diversos atores sociais disputam não só os sentidos das suas normas, mas afirmam dentro dos seus limites quem nós somos e quem pretendemos ser como comunidade política. Portanto, sustentam aquilo que nos constitui, democraticamente, o nosso nomos, o qual, como lembram Siegel e Post, estará sempre aberto e em disputa para novas interpretações, afirmações e revisões, nesse processo inconcluso de construção de identidades individuais e coletivas (nacionais ou regionais).

Por fim, esse caso da vaquejada nos leva às seguintes considerações (finais): 1) Teorias liberais progressistas são abrangentes e oferecem diferentes arranjos para a relação entre o constitucionalismo e a democracia. Entretanto, não há como negar que essas duas categorias teóricas e práticas experimentam uma permanente tensão ainda que, normativamente, alguns subestimem a sua centralidade, negando-a. Trata-se de uma tensão altamente produtiva e que nos casos controversos que envolvem direitos fundamentais, ora aumenta a temperatura do direito, ora a da política a exigir deliberação e decisão; 2) O procedimento de tomada de decisão e ela mesma devem ser dotados de legitimidade e autoridade, manejo este complexo, mas necessário para uma devida justificação dos regimes políticos; 3). A decisão não aniquila os desacordos que caracteri- 
zam as comunidades plurais contemporâneas; 4) Todas as pessoas devem ser igualmente respeitadas em suas diferenças; 5) As reações provocadas por uma dada decisão podem estimular disputas acerca dos sentidos da Constituição ampliando a participação, para além da esfera jurisdicional. Quer dizer, os juízes não têm e não devem ter o monopólio sobre a interpretação da Constituição, podendo esta ser compartilhada; 6) Ainda, as reações às decisões não só deslocam do Poder judiciário a palavra final, mas desencadeiam eventos políticos, sociais e culturais; 7) O caso da vaquejada expôs no STF diferentes interpretações, ora em favor do direito dos animais e pela proibição da crueldade, ora em favor da manifestação cultural desde que não resulte em crueldade. Provocou a sociedade, mobilizou a opinião pública e fez a política parlamentar assumir a controvérsia resultando em decisão contrária a que tomou o STF; 8) Em democracias constitucionais, a Constituição não é o que a Corte Suprema diz que ela é. Há de se considerar que os demais poderes e nós, o povo, são interpretes tão legítimos da Constituição quanto a Corte e não podemos ser demitidos de tal tarefa; 9) Mas essa é uma postura progressista na teoria constitucional e é sabido que ele disputa espaço no campo progressista, mas não só. Para o nosso desencantamento, há nesse momento no mundo e no nosso mundo (que é o Brasil) um movimento regressivo da teoria e da prática constitucional. Por regressivo refere-se às restrições de direitos e suas garantias, ao arbítrio institucional de governantes, parlamentares e juízes cujas decisões se divorciaram do compromisso com a Constituição.

\section{Referências}

BICKEL, Alexander M. The least dangerous branch. New Haven: Yale University Press, 1986.

CHUEIRI, Vera Karam de. Is there such thing as a radical constitution? In: BUSTAMANTE, Thomas; fernandes, Bernardo G. (Ed.) Democratizing constitutional law: perspective on legal theory and the legitimacy of constitutionalism. Switzerland: Springer, 2016a. p. 233-245.

. O Reencantamento do direito na filosofía e da filosofia no direito: Dworkin e a leitura moral da constituição. In: PERISSINOTTO, 
Renato et al. (Org.). Curso livre de teoria política. Curitiba: Appris, 2016b. p. 273-295.

COVER, Robert. Narrative, violence and the law:The essays of Robert Cover. Edited by Martha Minow, Michael Ryan and Austin Sarat.

Michigan: The University of Michigan Press, 1999.

DWORKIN, Ronald. Taking Rights Seriously. Cambridge, Mass.: Harvard University Press, 1982.

Press, 1985.

. A Matter of principle. Cambridge, Mass.: Harvard University . Law's Empire. Cambridge, Mass.: Harvard University Press, 1986.

. Justice for Hegdehogs. Cambridge, Mass. and London: The Belknap Press of Harvard University Press, 2011.

. A virtude soberana: a teoria e a prática da igualdade. Trad. Jussara Simões. São Paulo: Martins Fontes, 2012.

GODOY, Miguel Gualano de. Devolver a Constituição ao Povo: crítica à supremacia judicial e diálogos institucionais. Belo Horizonte: Fórum, 2017.

MOUFFE, Chantal. Agonistics: Thinking the world politically. New York and London: Verso, 2013.

NINO, Carlos Santiago. La Constitución de la Democracia Deliberativa. Trad. Roberto P. Saba. Barcelona: Gedisa, 2003.

PIRES, Thula Rafaela de Oliveira. Cass Sunstein: Do Republicanismo ao Minimalismo Judicial. In: VIEIRA, José Ribas (org.). Teoria Constitucional Norte-Americana contemporânea. Rio de Janeiro: Lumen Juris, 2011. p. 131-157.

POST, Robert; SIEGEL, Reva. Roe Rage: Democratic Constitutionalism and Backlash. Harvard Civil-Rights Civil-Liberties Law Review, Cambridge: Harvard University, v. 42. p. 373-433, 2007. 
. Democratic Constitutionalism. In: BALCKIN, Jack; SIEGEL, Reva (Ed.) Constitution in 2020. Oxford: Oxford University Press, 2009. p. 25-34.

. Constitucionalismo democrático. In: POST, Robert; SIEGEL, Reva. Constitucionalismo democrático: Por una reconciliácion entre Constitución y pueblo. Trad. Leonardo García Jaramillo. Buenos Aires: Siglo XXI, 2013. p. 31-41.

SAMPAIO, José Adércio Leite. Apresentação. In: SUNSTEIN, Cass. A Constituição Parcial. Trad. Manassés Teixeira Martins e Rafael Triginelli. Belo Horizonte, Del Rey, 2008. p. iii-xxvii.

SULTANY, Nimer. The State of Progressive Constitutional Theory: The Paradox of Constitutional Democracy and the Project of Political Justification. Harvard Civil Reights-Civil Liberties Law Review. [S.l.], v. 47, 2012.

SUNSTEIN, Cass. Beyond the Republican Revival. The Yale Law Journal, New Haven, v. 97, n. 8, 1.539-1.590, jul. 1988.

. The Partial Constitution. Cambridge: Harvard, 1993.

. Democracy and the problem of Free Speech: With a new Sustein, Afterword. New York: The Free Press, 1995.

. Why Societies Need Dissent. Cambridge: Harvard, 2003a.

. Of Snakes and butterflies: a reply. The Chicago Public Law and Legal Theory working Paper n. 35 University of Chicago, August 2006. Disponível em: https://papers.ssrn.com/sol3/papers.cfm?abstract id=924421. Acesso em: 14 ago. 2018.

. If People Would Be Outraged by their Rulings, Should Judges Care. University of Chicago Law School Chicago: Unbound, 2007. Disponível em: https://chicagounbound.uchicago.edu/cgi/ viewcontent.cgi? article $=12300 \&$ context $=$ journal_articles. Acesso em: 14 ago. 2018.

. Acuerdos Carentes de una teoría completa en derecho constitucional y otros ensayos. Cali: Universidad Icesi, 2010. 
. Legal Reasoning and Political Conflict. Second Edition. New York: Oxford University Press, 2018.

SUNSTEIN, Cass; VERMEULE, Adrian. Interpretation and Institutions. Michigan Law Review, Ann Arbor: Michigan University, v. 101, n. 4, p. 885-951, 2003.

Vera Karam de Chueiri é professora de Direito Constitucional dos Programas de Graduação e Pós-Graduação em Direito da UFPR. Pesquisadora do CNPq. Coordenadora e Pesquisadora do CCONS/UFPR. Diretora da Faculdade de Direito da UFPR para o quadriênio 2016-2020.

E-mail:vkchueiri@gmail.com

Endereço profissional: Praça Santos Andrade, n. 50, Curitiba, PR. CEP: 80020300 .

José Arthur Castillo de Macedo doutor em Direito do Estado pela UFPR, professor de Direito Constitucional e Teoria do Direito do Curso de Direito do IFPR, Campus Palmas, pesquisador do CCONS/UFPR e integrante da Comissão de Estudos Constitucionais da OAB/PR.

E-mail: josearthurcastillomacedo@gmail.com

Endereço profissional: Praça Santos Andrade, n. 50, Curitiba, PR. CEP: 80020300. 